\title{
MIT
}

\section{Highly Enantioselective Synthesis of Indazoles with a C3-Quaternary Chiral Center Using CuH Catalysis}

The MIT Faculty has made this article openly available. Please share how this access benefits you. Your story matters.

\begin{tabular}{|l|l|}
\hline As Published & $10.1021 /$ JACS.0C04286 \\
\hline Publisher & American Chemical Society (ACS) \\
\hline \hline Version & Original manuscript \\
\hline Citable link & https://hdl.handle.net/1721.1/132536 \\
\hline Terms of Use & Creative Commons Attribution-Noncommercial-Share Alike \\
\hline Detailed Terms & http://creativecommons.org/licenses/by-nc-sa/4.0/ \\
\hline
\end{tabular}




\title{
Highly Enantioselective Synthesis of Indazoles with a C3-Qua- ternary Chiral Center Using CuH Catalysis
}

\author{
Yuxuan Ye, ${ }^{1}$ Ilia Kevlishvili, ${ }^{2}$ Sheng Feng,,${ }^{1}$ Peng Liu, ${ }^{2 *}$ and Stephen L. Buchwald ${ }^{1 *}$ \\ ${ }^{1}$ Department of Chemistry, Massachusetts Institute of Technology, Cambridge, Massachusetts 02139, United States \\ ${ }^{2}$ Department of Chemistry, University of Pittsburgh, Pittsburgh, Pennsylvania 15260, United States
}

\begin{abstract}
C3-substituted $1 H$-indazoles are useful and important substructures in many pharmaceuticals. Methods for direct C3functionalization of indazoles are relatively rare, compared to reactions developed for the more nucleophilic N1 and N2 positions. Herein, we report a highly $\mathrm{C} 3$-selective allylation reaction of $1 \mathrm{H}-\mathrm{N}$-(benzoyloxy)indazoles using $\mathrm{CuH}$ catalysis. A variety of $\mathrm{C} 3$-allyl $1 H$-indazoles with quaternary stereocenters were efficiently prepared with high levels of enantioselectivity. Density functional theory (DFT) calculations suggest that the indazole addition to copper allyl complex proceeds through an enantioselectivity-determining sixmembered Zimmerman-Traxler-type transition state. The enantioselectivity is governed both by the ligand-substrate steric interactions and the steric repulsions with the pseudoaxial substituent in the six-membered allylation transition state.
\end{abstract}

\section{INTRODUGTION}

The functionalization of nitrogen-containing heterocycles is a key area of research in organic synthesis due to the importance of these molecules in pharmaceutical applications. ${ }^{1}$ In particular, the preparation of indazole derivatives is of great interest as a result of their versatile pharmacological activities ${ }^{2}$ and their utility as indole bioisosteres in medicinal chemistry (Figure 1a). ${ }^{3}$ The direct alkylation of indazoles is one of the most efficient methods to derivatize these molecules for medicinal chemistry studies. Conventionally, indazoles are employed as nucleophiles in these transformations, and either the N1- or N2-isomer is formed, depending on the reaction conditions., ${ }^{4,5}$ Direct C3-alkylation processes, however, are rare due to the lack of nucleophilicity at the C3-position, even when N1- or N2-position is protected (Figure 1b). ${ }^{6}$

Recently, we developed a method to prepare chiral alkylated indoles through a $\mathrm{CuH}$-catalyzed nucleophilic alkylation reaction. ${ }^{7}$ By employing $\mathcal{N}$-(benzoyloxy)indoles as electrophiles and with the appropriate choice of ligand, selective $\mathrm{N}$-alkylation or C-alkylation was achieved. Compared to conventional alkylation reactions, where indoles are used as nucleophiles, ${ }^{8}$ the regioselectivity of this alkylation protocol was dictated by the catalyst, rather than the intrinsic nucleophilicities of the indole. ${ }^{9} \mathrm{We}$ envisioned that this umpolung strategy ${ }^{10}$ could be expanded to other nitrogen-containing heterocycles, allowing us to achieve unconventional regioselectivity in the functionalization process of these heterocyclic molecules. Specifically, in the case of indazoles, we were hopeful that by employing $\mathcal{N}$-(benzoyloxy)indazoles as electrophiles, the typically observed N1- or N2-regioselectivity in the nucleophilic substitution reactions could be overrode, and C3-alkylated indazoles might be accessed (Figure 1c). (a) Indazole-containing biologically active molecules

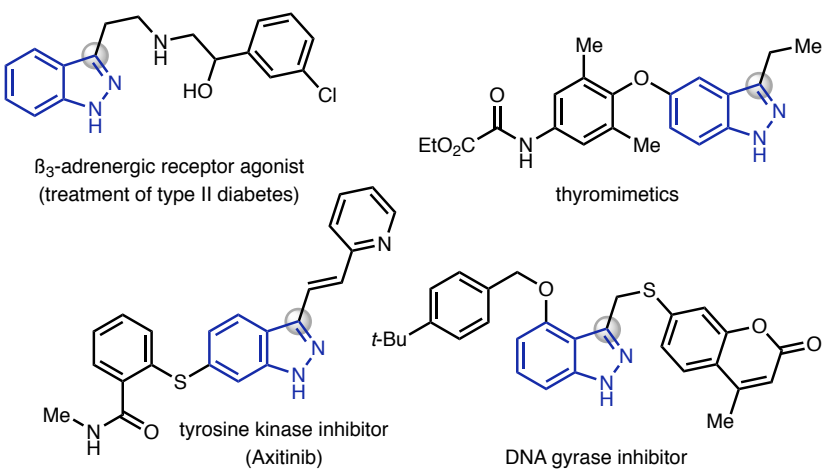

(b) Regioselectivity of conventional indazole alkylation reactions

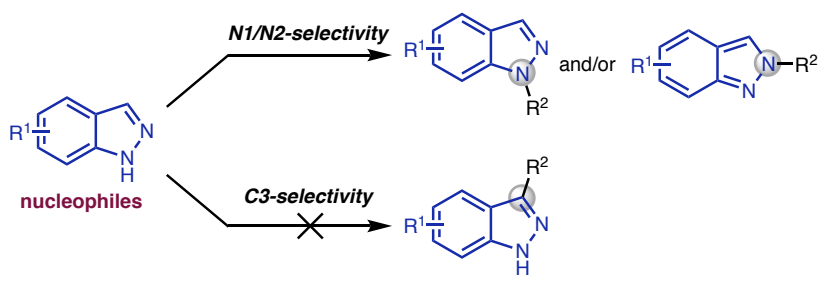

(c) Proposed asymmetric C3-alkylation of indazole electrophiles

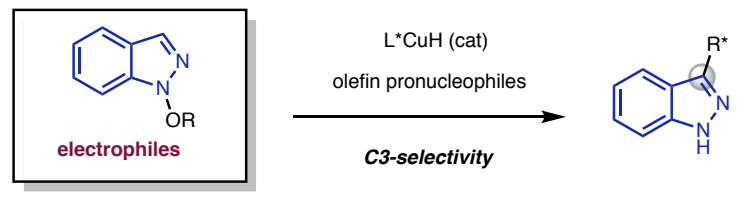

Figure 1. (a) Indazole-containing biologically active molecules. (b) Regioselectivity of conventional indazole alkylation reactions. (c) Asymmetric C3-allylation of indazole electrophiles. 


\section{RESULTS AND DISGUSSION}

We commenced our studies by investigating the reaction between $\mathbf{1 a}$ (Table 1, 1, R3=H) and a variety of carbon-carbon double bond-containing pronucleophiles in the presence of CuH catalyst (Scheme S1). 1,1-disubstituted allene $\mathbf{2 a}$ (Table 1, $\mathbf{2}, \mathrm{R}^{1}=\mathrm{Ph}, \mathrm{R}^{2}=\mathrm{Me}$ ) was found to react efficiently with $\mathbf{1} \mathbf{a}$ using $\mathrm{Ph}-\mathrm{BPE}$ as the ligand, providing allyl indazole $\mathbf{3 a}$ in good yield with an excellent level of enantioselectivity (Table 1, 3a). The allylation reaction exhibited excellent C3-regioselectivity, illustrating the impact of this polarity reversal strategy in accessing novel regioselectivity in nitrogen-containing heterocycle functionalization reactions. Notably, using 1,1-disubstituted allenes as the coupling partners, acyclic quaternary stereocenters, which are challenging to construct, ${ }^{11}$ are installed efficiently at the $\mathrm{C} 3$-position of indazole products.

We next explored the scope of this transformation. A variety of 1-alkyl-1-arylallenes are found to couple efficiently to $\mathcal{N}$-(benzoyloxy)indazole electrophiles (Table 1). Substituents including 4-methoxy (3b), 2-fluoro (3c), 4-bromo (3g), 3-chloro (3i), 4trifluoromethyl $(\mathbf{3} \mathbf{j})$, and 2-methyl $(\mathbf{3 k})$ on the phenyl ring of the allenes are well tolerated. Allenes containing heterocycles, such as furan $(\mathbf{3 d})$, 2-methoxypyridine $(\mathbf{3 e})$, and $\mathcal{N}$-Ts-pyrrole $(\mathbf{3 f})$, are also compatible in the reaction. We observed a slight decrease in both efficiency and enantioselectivity with the increasing steric hindrance of alkyl substituents on the allenes. Methyl$(\mathbf{3 a})$, ethyl- $(\mathbf{3 g})$, isobutyl- (31), and cyclopropyl- (3h) substituted indazoles were prepared from the corresponding allenes with decreasing enantiomeric ratios (99.5:0.5 to 92:8). In addition, an indazole derivative with a fused dihydropyran (3i) was prepared from a chromane-derived allene efficiently.

Table 1. Substrate Scope for the C3-Allylation of Indazole Electrophiles. ${ }^{a}$

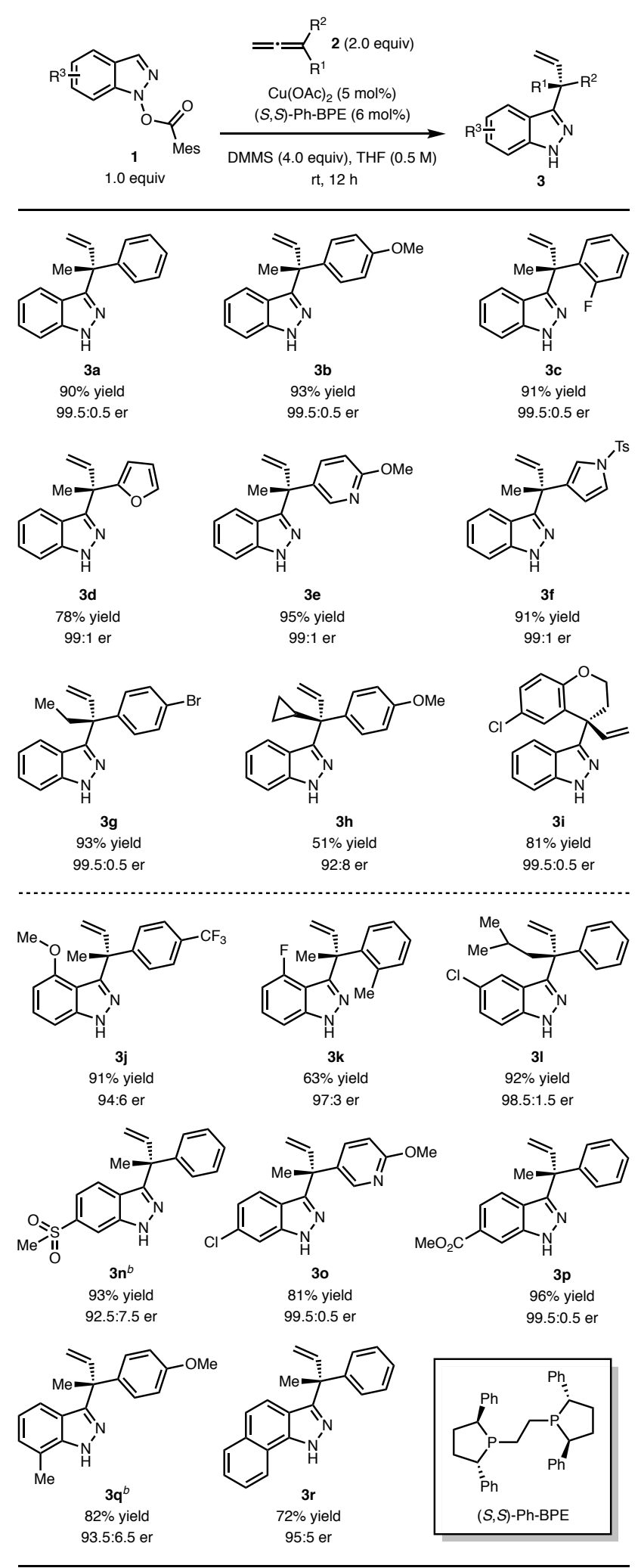

${ }^{a}$ All yields represent average isolated yields of two runs, performed with $0.5 \mathrm{mmol}$ of indazole electrophile. ${ }^{b} 60^{\circ} \mathrm{C}$.

The reaction is broadly tolerant of substituents appended to the indazole electrophiles, including 4-methoxy $(\mathbf{3 j})$, 4-fluoro (3k), 5-chloro (31), 6-methylsulfonyl (3n), 6-chloro (3o), 6-carbomethoxy $(\mathbf{3 p})$, and 7-methyl $(\mathbf{3 q})$. Moreover, a benzoindazole electrophile was also found to be a competent coupling partner in this transformation $(\mathbf{3 r})$. 
To briefly demonstrate the potential synthetic utility of these coupling products, indazole $\mathbf{3 b}$ was converted to a primary alcohol in good yield under hydroboration-oxidation process (Scheme 1, a). Furthermore, the terminal double bond of $\mathbf{3 b}$ could be easily reduced to an ethyl group, generating a stereocenter containing both methyl and ethyl substituents with excellent enantioselectivity (Scheme 1, b). An Ullmann coupling reaction of $\mathbf{3 a}$ with an aryl iodide was performed successfully as well. Although transition-metal-catalyzed $\mathrm{N}$-arylation of indazoles usually generates a mixture of N1- and N2-arylated products, ${ }^{12}$ high N1-selectivity (N1:N2>20:1) of $\mathbf{3 b}$ was observed in this case, presumably due to the steric hindrance of the C3-substituent (Scheme 1, c).

Scheme 1. Further Functionalizations of Allylated Indazoles. ${ }^{a}$

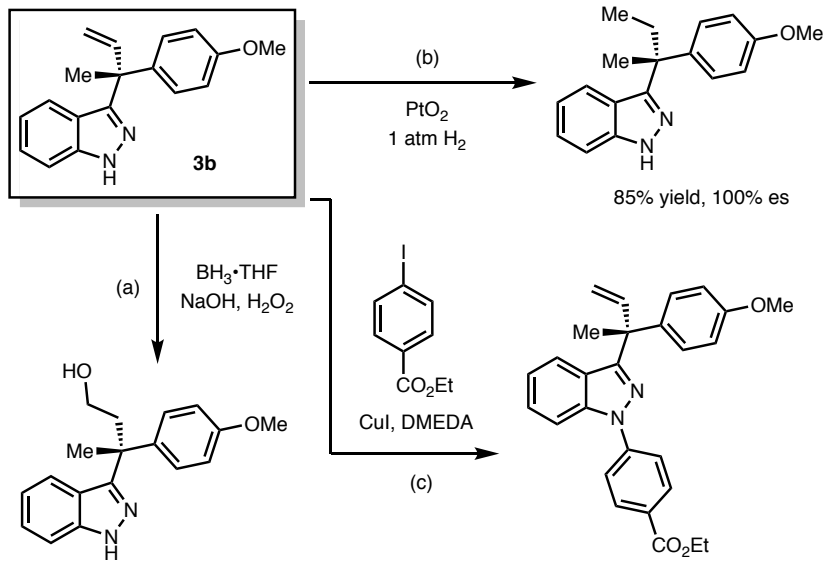

$71 \%$ yield, $100 \%$ es

$95 \%$ yield, $100 \%$ es, N1/N2 > 99:1

aReactions were conducted on $0.2 \mathrm{mmol}$ scale. See the Supporting Information for detailed conditions.

We next investigated the mechanism and origin of selectivity of the allylation of $\mathbf{1 a}$ using density functional theory (DFT) calculations (Figure 2). The hydrocupration of allene $\mathbf{2} \mathbf{a}$ with copper hydride $\mathbf{4}$ takes place via TS1 with a $15.9 \mathrm{kcal} / \mathrm{mol}$ activation energy (see the Supporting Information, Figure S1, for other less favorable hydrocupration pathways). This step leads to the irreversible formation of the Z-isomer of the terminal allylic copper species $(\mathbf{5})$. Complex $\mathbf{5}$ can rapidly isomerize to form either diastereomers of the tertiary benzylic copper intermediate 6 , which undergoes subsequent isomerization to afford the thermodynamically more stable $E$-isomer of the terminal allylic copper (7). ${ }^{13 e}$ Subsequent indazole addition may occur at either face of the $\mathrm{C}=\mathrm{C}$ bond of $\mathbf{5}$ or $\mathbf{7}$. These four competing pathways all involve six-membered Zimmerman-Traxler-type transition states ${ }^{14}$ (TS2a-d). Here, the $\mathrm{G}-\mathrm{C}$ bond formation and the dissociation of 2,4,6-trimethylbenzoate anion are a concerted process, leading directly to $3 H$-indazole complexes $(\mathbf{8 a}-$ d), which form the $1 H$-indazole product upon tautomerization. Our calculations suggest that the oxidative addition of indazole $1 \mathbf{a}$ with $\mathbf{7}$ to form $\mathrm{Cu}(\mathrm{III})$ intermediates requires higher activation energies (see SI, Figure S4, for details). The enantioselectivity of the C3-allylation product is determined in the indazole addition step (TS2). Among the four competing transition states, TS2a and TS2b originating from the Z-allyl complex $\mathbf{5}$ are both disfavored $(3.3$ and $8.0 \mathrm{kcal} / \mathrm{mol}$ higher than TS2c, respectively) due to the pseudoaxial placement of the bulky phenyl group, which leads to increased repulsions with the indazole (Figure 2B). In TS2c and TS2d, the smaller methyl group is placed at the pseudoaxial position and thus the steric repulsions about the forming $\mathrm{C}-\mathrm{C}$ bond are decreased. From intermediate
7, the addition of the indazole (TS2d) to form the $(S)$ product is $5.4 \mathrm{kcal} / \mathrm{mol}$ less favorable than the addition to form the $(R)$ product $(\mathbf{T S 2} \mathbf{c})$. The relative instability of $\mathbf{T S 2} \mathbf{d}$ arises from unfavorable steric repulsions between the $(S, S)$-Ph-BPE ligand and the 2,4,6-trimethylbenzoate leaving group. In TS2d, the bulky leaving group is placed in the quadrant occupied by a "proximal" phenyl group on the ligand (Figure 2G). By contrast, in TS2c, the leaving group is in a less occupied quadrant with a "distal" phenyl group. The increased ligand-substrate steric repulsions in TS2d are evidenced by the more significant distortion of the Ph-BPE ligand in TS2d than in TS2c $\left(\Delta \Delta E_{\text {dist-Ph-BPE }}\right.$ $=3.7 \mathrm{kcal} / \mathrm{mol}$, see Figure S2). 

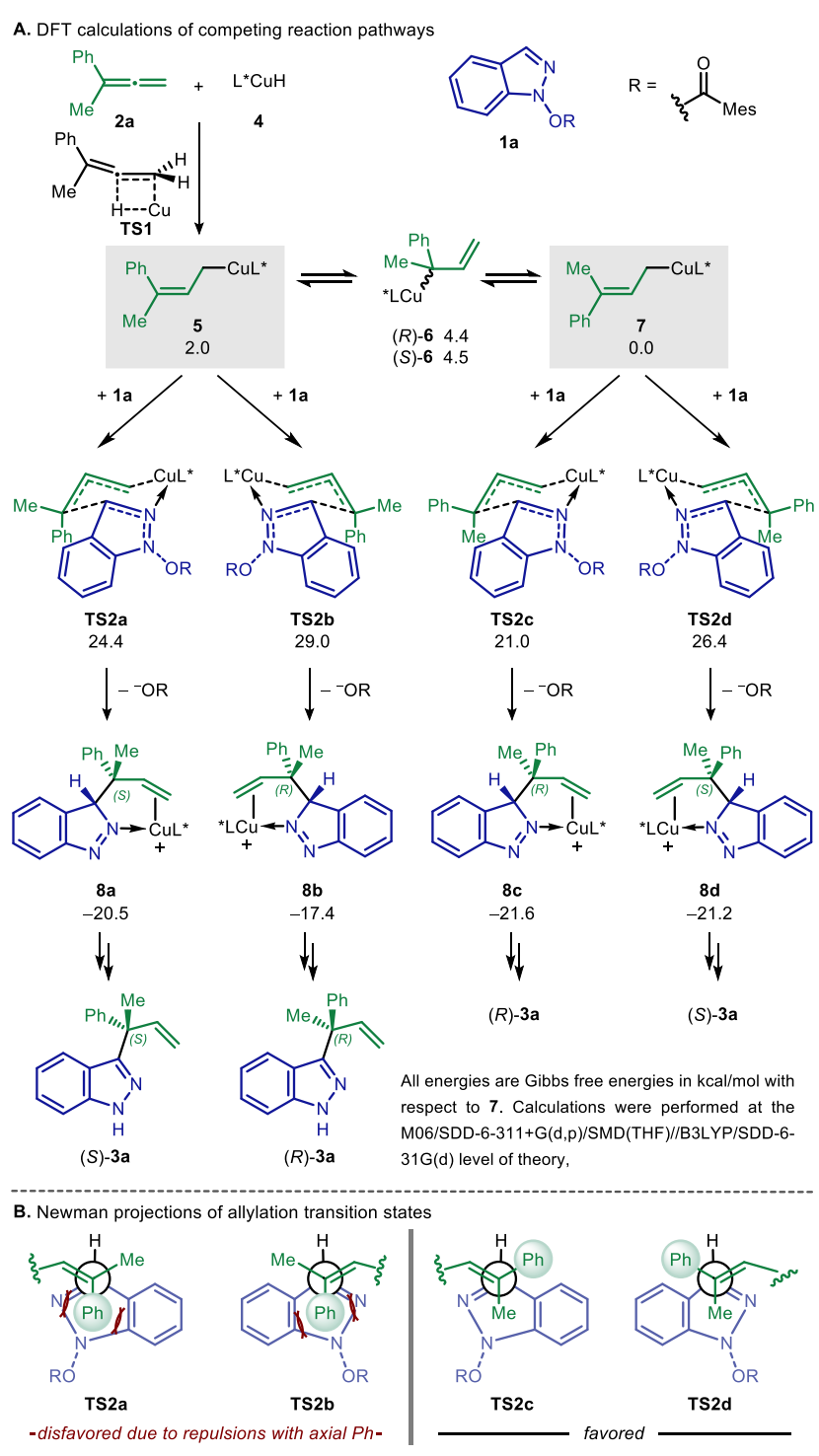

C. Origin of enantioselectivity
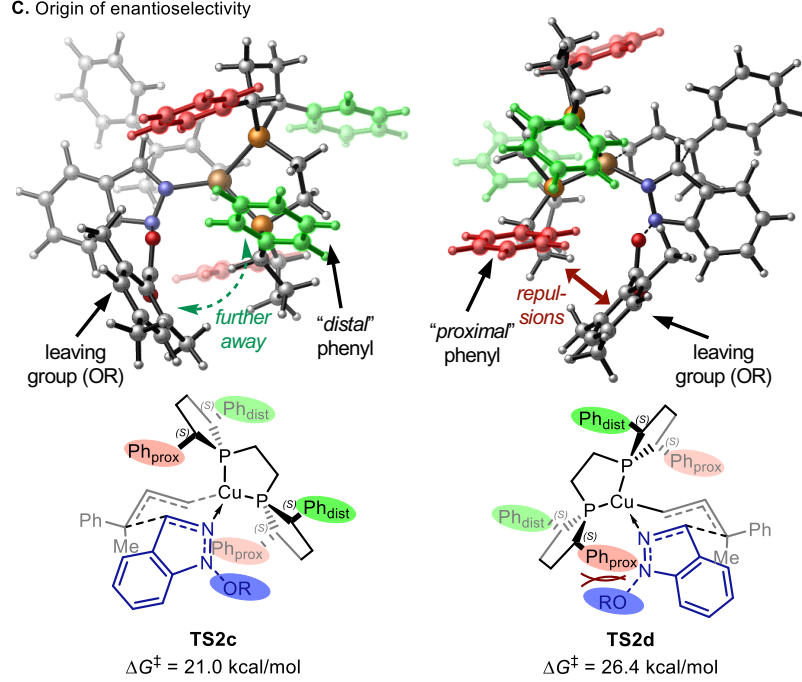

Figure 2: Computational studies of the mechanisms of the allylation of indazole $\mathbf{1 a}$ and the origin of enantioselectivity.

\section{CONGLUSIONS}

In summary, we have developed a method for the preparation of C3-allylated indazoles bearing quaternary stereocenters in high yield with excellent levels of enantioselectivity using $\mathrm{CuH}$ catalysis. Key to the success of this unique C3-selectivity in indazole chemistry is the use of an umpolung strategy: in contrast to the conventional use of indazoles as nucleophiles, electrophilic indazoles $(\mathcal{N}$-(benzoyloxy)indazoles) are employed as electrophiles in the reaction. Expanding this a polarity reversal strategy to achieve novel reactivities in other nitrogen-containing heterocycle functionalization reactions is currently underway.

\section{ASSOGIATED GONTENT}

Supporting Information.

The supporting Information is available free of charge on the ACS Publications website.

Experimental details and computational data (PDF)

Spectroscopic data (PDF)

\section{AUTHOR INFORMATION}

\section{Corresponding Author \\ *sbuchwal@mit.edu \\ *pengliu@pitt.edu}

\section{Notes}

The authors declare no competing financial interest.

\section{AGKNOWLEDGMENT}

The authors thank Solvias AG for donations of ligands used in this project. We are grateful to the National Institutes of Health (R35-GM122483, R35-GM128779). The content is solely the responsibility of the authors and does not necessarily represent the official views of the National Institute of Health. We thank Yujing Zhou, Drs. Richard Liu, Scott McCann, and Christine Nguyen for their advice on the preparation of this manuscript. We acknowledge Drs. Peter Müller (MIT) and Charlene Tsay (MIT) for X-ray crystallographic analysis. We thank the National Institutes of Health for a supplemental grant for the purchase of supercritical fluid chromatography (SFG) equipment (GM058160-17S1). I.K. is grateful to the University of Pittsburgh and the Pittsburgh Quantum Institute for fellowships. DFT calculations were performed at the Center for Research Computing at the University of Pittsburgh and the Extreme Science and Engineering Discovery Environment (XSEDE) supported by the NSF.

\section{REFERENGES}

(1) (a) Vitaku, E.; Smith, D. T.; Njardarson, J. T. Analysis of the Structural Diversity, Substitution Patterns, and Frequency of Nitrogen Heterocycles among U.S. FDA Approved Pharmaceuticals. 7. Med. Chem., 2014, 57, 10257-10274. (b) Lamberth, C.; Dinges, J. Bioactive Heterocyclic Compound Classes: Pharmaceuticals and Agrochemicals; WileyVCH: Weinheim, Germany, 2012.

(2) Cerecetto, H.; Gerpe, A.; González, M.; Arán, V. J.; de Ocáriz, C. O. Pharmacological Properties of Indazole Derivatives: Recent Developments. Mini-Reviews in Medicinal Chemistry 2005, 5, 869-878.

(3) (a) Brown, N. Bioisosterism in Medicinal Chemistry; Wiley-VCH: Weinheim, Germany, 2012. (b) Ainsworth, C. Indazole Analog of Tryptamine: A New Synthesis of Indazoles. F. Am. Chem. Soc. 1957, 79, 
5242-5245. (c) Ainsworth, C. The Indazole Analog of Serotonin. F. Am. Chem. Soc. 1957, 79, 5245-5247.

(4) Reviews on indazole synthesis: (a) Schmidt, A.; Beutler, A.; Snovydovych, B. Recent Advances in the Chemistry of Indazoles. Eur. 7. Org. Chem. 2008, 4073-4095. (b) Zhang, S.-G.; Liang, C.-G.; Zhang, W.-H. Recent Advances in Indazole-Containing Derivatives: Synthesis and Biological Perspective. Molecules 2018, 23, 2783-2824.

(5) Examples of indazoles alkylation with N1/N2 regioselectivity: (a) Hunt, K. W.; Moreno, D. A.; Suiter, N.; Clark, C. T.; Kim, G. Selective Synthesis of 1-Functionalized-Alkyl-1H-Indazoles. Org. Lett. 2009, 11, 5054-5057. (b) Lin, M.-H.; Liu, H.-J.; Lin, W.-C.; Kuo, C.-K.; Chuang, T.-H. Regioselective Synthesis of $2 H$-Indazoles through $\mathrm{Ga} / \mathrm{Al}$ - and Al-Mediated Direct Alkylation Reactions of Indazoles. Org. Biomol. Chem. 2015, 13, 11376-11381. (c) Haydl, A. M.; Breit, B. Regioand Enantioselective Synthesis of N-Substituted Pyrazoles by Rhodium-Catalyzed Asymmetric Addition to Allenes. Angerw. Chem., Int. Ed. 2015, 54, 7149-7153. (d) Slade, D. J.; Pelz, N. F.; Bodnar, W.; Lampe, J. W.; Watson, P. S. Indazoles: Regioselective Protection and Subsequent Amine Coupling Reactions. f. Org. Chem. 2009, 74, 6331-6334. (e) Luo, G.; Chen, L.; Dubowchik, G. Regioselective Protection at N-2 and Derivatization at C-3 of Indazoles. F. Org. Chem. 2006, 71, 53925395.

(6) A rare example of direct C3-alkylation using indazoles as nucleophiles: Campetalla, S.; Palmieri, A.; Petrini, M. Synthesis of 3-(Tosylalkyl)indazoles and their Desulfonylation Reactions-A New Entry to 3Substituted Indazoles by an Unprecedented Friedel-Crafts Process. Eur. 7. Org. Chem. 2009, 3184-3188.

(7) Ye, Y.; Kim, S.-T.; Jeong, J.; Baik, M.-H.; Buchwald, S. L. CuHCatalyzed Enantioselective Alkylation of Indole Derivatives with Ligand-Controlled Regiodivergence. F. Am. Chem. Soc. 2019, 141, 39013909.

(8) (a) Chen, J. B.; Jia, Y. X. Recent Progress in Transition-MetalCatalyzed Enantioselective Indole Functionalizations. Org. Biomol. Chem. 2017, 15, 3550-3567. (b) Bandini, M.; Eichholzer, A. Catalytic Functionalization of Indoles in a New Dimension. Angew. Chem., Int. Ed. 2009, 48, 9608-9644.

(9) (a) Lakhdar, S.; Westermaier, M.; Terrier, F.; Goumont, R.; Boubaker, T.; Ofial, A. R.; Mayr, H. Nucleophilic Reactivities of Indoles. 7. Org. Chem. 2006, 71, 9088-9095. (b) Otero, N.; Mandado, M.; Mosquera, R. A. Nucleophilicity of Indole Derivatives: Activating and Deactivating Effects Based on Proton Affinities and Electron Density Properties. F. Phys. Chem. A 2007, 111, 5557-5562.

(10) Seebach, D. Methods of Reactivity Umpolung. Angew. Chem. Int. Ed. Engl. 1979, 18, 239-258.

(11) (a) Kieslich, K.; Koch, H.-J.; Kosmol, H.; Rufer, C.; Schröder, E.; Vössing, R. Totalsynthese von Natürlichem Östradiolmethyläther. Tetrahedron Lett. 1966, 7, 2321-2330. (b) Fuji, K. Asymmetric Creation of Quaternary Carbon Centers. Chem. Rev. 1993, 93, 2037-2066. (c) Corey, E. J.; Guzman-Perez, A. The Catalytic Enantioselective Construction of Molecules with Quaternary Carbon Stereocenters. Angew. Chem. Int. Ed. 1998, 37, 388-401. (d) Christoffers, J.; Mann, A. Enantioselective Construction of Quaternary Stereocenters. Angew. Chem. Int. Ed. 2001, 40, 4591-4597. (e) Denissova, I.; Barriault, L. Stereoselective
Formation of Quaternary Carbon Centers and Related Functions. Tetrahedron 2003, 59, 10105-10146. (f) Douglas, C. J.; Overman, L. E. Catalytic Asymmetric Synthesis of All-Carbon Quaternary Stereocenters. Proc. Natl. Acad. Sci. U. S. A. 2004, 101, 5363-5367. (g) Trost, B. M; Jiang, C. Catalytic Enantioselective Construction of All-Carbon Quaternary Stereocenters. Synthesis 2006, 369-396. (h) Das, J.; Marek, I. Enantioselective Synthesis of All-Carbon Quaternary Stereogenic Centers in Acyclic Systems. Chem. Commun. 2011, 47, 4593-4623. (i) Quasdorf, K. W.; Overman, L. E. Catalytic Enantioselective Synthesis of Quaternary Carbon Stereocentres. Nature 2014, 516, 181-191. (j) Gibian, H.; Marek, I.; Minko, Y.; Pasco, M.; Mejuch, T.; Gilboa, N.; Chechik, H.; Das, J. P. All-Carbon Quaternary Stereogenic Centers in Acyclic Systems through the Creation of Several C-C Bonds per Chemical Step. F. Am. Chem. Soc. 2014, 136, 2682-2694. (k) Liang, T.; Rivas, F. All-Carbon Quaternary Centers in Natural Products and Medicinal Chemistry: Recent Advances. Tetrahedron 2016, 72, 6729-6777. (l) Feng, J.; Holmes, M.; Krische, M. J. Acyclic Quaternary Carbon Stereocenters via Enantioselective Transition Metal Catalysis. Chem. Rev. 2017, 117, 12564-12580.

(12) (a) Kazzouli, S. E.; Guillaumet, G. Functionalization of Indazoles by Means of Transition Metal-Catalyzed Cross-Coupling Reactions. Tetrahedron 2016, 72, 6711-6727. (b) Antilla, J. C.; Baskin, J. M.; Barder, T. E.; Buchwald, S. L. Copper-Diamine-Catalyzed N-Arylation of Pyrroles, Pyrazoles, Indazoles, Imidazoles, and Triazoles. F. Org. Chem. 2004, 69, 5578-5587.

(13) For asymmetric allylation using allyl copper species, see: (a) Holmes, M.; Schwartz, L. A.; Krische, M. J. Intermolecular Metal-Catalyzed Reductive Coupling of Dienes, Allenes, and Enynes with Carbonyl Compounds and Imines. Chem. Rev. 2018, 118, 6026-6052. (b) Shao, X.; Li, K.; Malcolmson, S. J. Enantioselective Synthesis of Anti1,2-Diamines by $\mathrm{Cu}$-Catalyzed Reductive Coupling of Azadienes with Aldimines and Ketimines. F. Am. Chem. Soc. 2018, 140, 7083-7087. (c) Li, M.; Wang, J.; Meng, F. Cu-Catalyzed Enantioselective Reductive Coupling of 1,3-Dienes and Aldimines. Org. Lett. 2018, 20, 7288-7292. (d) Liu, R. Y.; Yang, Y.; Buchwald, S. L. Regiodivergent and Diastereoselective CuH-Catalyzed Allylation of Imines with Terminal Allenes. Angew. Chem. Int. Ed. 2016, 55, 14077-14080. (e) Li, C.; Liu, R. Y.; Jesikiewicz, L. T.; Yang, Y.; Liu, P.; Buchwald, S. L. CuH-Catalyzed Enantioselectvie Ketone Allylation with 1,3-Dienes: Scope, Mechanism, and Application. F. Am. Chem. Soc. 2019, 141, 5062-5070.

(14) (a) Grayson, M. N.; Krische, M. J.; Houk, K. N. RutheniumCatalyzed Asymmetric Hydrohydroxyalkylation of Butadiene: The Role of the Formyl Hydrogen Bond in Stereochemical Control. f. Am. Chem. Soc. 2015, 137, 8838-8850. (b) Mejuch, T.; Gilboa, N.; Gayon, E.; Wang, H.; Houk, K. N.; Marek, I. Axial Preferences in Allylation Reactions via the Zimmerman-Traxler Transition State. Acc. Chem. Res. 2013, 46, 1659-1669. (c) Kim, S. W.; Meyer, C. C.; Mai, B. K.; Liu, P. ; Krische, M. J. Inversion of Enantioselectivity in Allene Gas versus Allyl Acetate Reductive Aldehyde Allylation Guided by MetalCentered Stereogenicity: An Experimental and Computational Study. ACS Catal. 2019, 9, 9158-9163. 